\title{
A NEW APPROACH TO A HIGH EFFICIENCY INDUCTIVE STORE
}

\author{
By: \\ R. C. Zowarka \\ J. P. Kajs \\ S. B. Pratap \\ J. H. Price \\ W. F. Weldon \\ J. Weldon \\ J.A. Pappas
}

Fifth EML Conference, Destin, FL, April 2-5, 1990

IEEE Transactions on Magnetics, vol. 27, no. 1, January 1991, pp. 384 - 389

PR - 121

Center for Electromechanics

The University of Texas at Austin

PRC, Mail Code R7000

Austin, TX 78712

(512) 471-4496 


\title{
A NEW APPROACH TO A HIGH EFFICIENCY INDUCTIVE STORE
}

\author{
R.C. Zowarka, Jr., J.P. Kajs, S.B. Pratap, J.H. Price, and W.F. Weldon
}

Center for Electromechanics

The University of Texas at Austin

10100 Burnet Road, Building 133

Austin, TX 78758-4497

J.A. Pappas and J.M. Weldon

Parker Kinetic Design, Inc.

$8303 \mathrm{MoPac}$, Suite 240

Austin, TX 78759-8369

\begin{abstract}
In the Spring of 1989, Parker Kinetic Design, Inc. (PKD) and the Center for Electromechanics at The University of Texas at Austin (CEM-UT) conducted a study to examine the basic technologies to be used in the construction and operation of a feasible and reliable electromagnetic (EM) gun system. This work was performed for Brown and Root Vickers, Ltd. (BRV) in response to a feasibility analysis requirement of the Royal Armament and Development Establishment (RARDE), Ministry of Defence (MD), of the United Kingdom.
\end{abstract}

The report summarizing this study focused on the analysis and evaluation of the suitability and applicability of various pulsed power supply options for the performance goals of the RARDE EM gun program. The existing technologies considered included batteries, compulsators, capacitors, and homopolar generators (HPGs). Primary performance specifications for the electrical energy railgun system were that it be capable of providing $12 \mathrm{MJ}$ of muzzle energy; velocities between 2.0 and 3.5 $\mathrm{km} / \mathrm{s}$; and a repetitive shot rate of up to 10 shots per day, with no more than a 30 -min interval between shots. In addition, the recommended system needed to be reliable, easily maintainable, and capable of routinely firing large numbers of shots. Strict adherence to the goal of designing a system based only on demonstrated technology results in power supplies that are prohibitively expensive and large. As a consequence, candidate system designs represent a modest extrapolation from demonstrated technology well within an acceptable design envelope.

A new topology has been developed for a highly efficient inductive store suitable for pulsed-power applications. The new design features high $L / R$ ratios without having to cryogenically cool the conductors. This allows for high efficiency charging of the inductor from low impedance dc sources such as batteries or HPGs. The new inductor design produces very low external flux, which makes it suitable for laboratory applications where magnetic pressures on adjacent conductive structures and $E M$ interference noise introduced into control and instrumentation systems is a concern. The inductor may be fabricated in modules for cost effectiveness and ease of assembly.

\section{System Study Leading to Inductor Specification}

The energy requirements for the prime power source were derived using a simplified solid armature barrel code. To calibrate the effectiveness of this simulation, the current waveform for CEM-UT singleshot gun (SSG) test \#6 was approximated with a trapezoidal waveform and analyzed with the barrel code. Good agreement was seen between the measured breech energy and the barrel-input energy predicted by the simulation. The breech-energy requirements to produce $12 \mathrm{MJ}$ of kinetic energy in the projectile were established by running the simple simulation. Results of test \#6 were analyzed for demonstrated transfer efficiencies from the inductor to the railgun (fig. 1). This demonstrated transfer efficiency was then applied to the breech energy requirement to calculate the required inductive energy.
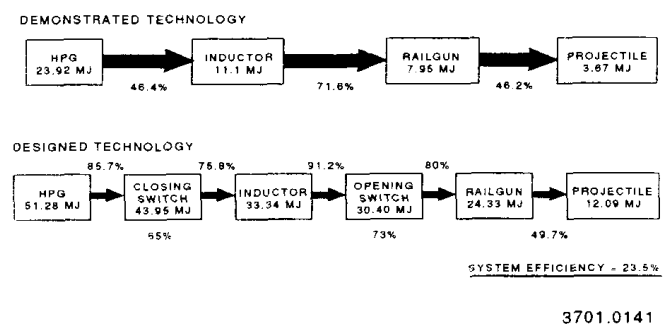

Figure 1. Component efficiencies for HPG based power supply

The geometry of an HPG/inductor system that would deliver the required inductive energy was established. To accomplish this, the required inductive energy was divided by the energy available from an arbitrary number of Balcones HPGs [1] running at design speed (15 MJ stored energy), in order to establish the transfer efficiency. It was found that four full-energy generators operating at a transfer efficiency of $65 \%$ would accomplish the design goals. An obvious area for performance gain was in the transfer efficiency from the HPG to the inductor. The Balcones guided electromechanic defense interceptor (GEDI) inductors [2] operate at a transfer efficiency of $46 \%$. A serious engineering challenge was identified in the inductor design and the proposed solution is described in the following sections.

\section{Staged Discharge}

An analysis of several options shows that the most efficient manner in which to run the new inductive energy store system is by stage discharging of the inductive stores. The process by which this conclusion was drawn is described here. It begins with the assumption that there is a peak allowable current at which the gun can operate. A certain performance is required that, given the system efficiency, determines the peak energy requirement for the inductor. With current fixed, inductance must be increased to achieve the stored- 
energy requirement. If the system has only one inductor, the allowable rate of current decay cannot be very steep, otherwise the average-to-peak acceleration ratio suffers and, at lower average accelerations, the required gun performance is not achieved. If the average acceleration does not fall off during the shot, then significant energy is left in the inductor at the end of the acceleration interval (when the projectile reaches the end of the barrel). That energy was paid for in changing the inductor and is therefore wasted; however, by staging multiple inductors (of lower inductance amounting to the total stored energy necessary to accomplish the launch), the rate of current decay or energy extraction from any given inductor increases. In order to hold the current delivered to the gun at an approximately constant level, the inductor current is staged into the gun at appropriate intervals. In this manner, acceleration (which is proportional to the current squared) is held at a higher average level and the individual inductors are more completely depleted of energy. A very small amount remains at the end of the test.

An approximation of the energy left in the inductors at the end of the discharge is available from the barrel simulation. This amount is added to the breech-energy requirement and one-fourth of the total is equated to the energy stored in a single inductor.

\section{Sivine Inductors for a Homopolar Generator System}

The peak design current for the Balcones HPG is used in the inductive energy equation to solve for the inductance. The HPG is modeled electrically as a capacitor. From the relations for the transfer efficiencies of RLC circuits, a total allowable circuit resistance can be calculated based on the required transfer efficiency of $65 \%$. The internal resistance of the Balcones HPG is well characterized and nominal values for interconnecting busbar impedances and opening switches can be calculated. When these contributions are summed and subtracted from the allowable circuit resistance, the result is the design objective for the inductor's resistance. The result of this calculation indicates that the new inductors require an $L / R$ time constant of $1.41 \mathrm{~s}$, whereas the GEDI coaxial inductors on the Balcones system have a time constant of $0.6 \mathrm{~s}$.

\section{Topology for Enhanced Efficiency}

Mr. John Price found in studying the Balcones GEDI inductors that the inner coaxial conductors dominate the resistance of the inductor. Calculations indicate that the cross section of these conductors may be arbitrarily increased, making them larger in diameter, and, in turn, allowing control of the inductor's resistance. As this is done, the topology changes from a coaxial to a toroidal geometry; however, a penalty is incurred in doing this. This is easily seen by applying Ampere's Law at the outer diameter of the inner conductors:

$$
\oint \mathrm{H} \bullet \mathrm{dl}=\mathrm{I}
$$

where

$$
\begin{aligned}
\mathrm{H}= & \text { magnetic field intensity } \\
\mathrm{dl}= & \text { differential length along the closed path } \\
& \text { encircling the current, } \mathrm{I}
\end{aligned}
$$

By tracing a circumferential path along constant values of the magnetic field intensity and evaluating the line integral, it is found that where

$$
\mathrm{H}=\frac{\mathrm{I}}{2 \pi \mathrm{r}}
$$

$$
\begin{aligned}
\mathbf{r} & =\text { radius just outside the inner conductors } \\
\mathrm{I} & =\text { total current enclosed by the } \\
& \text { circumferential path }
\end{aligned}
$$

In a linear system, magnetic field density is directly proportional to the magnetic field intensity; therefore, by increasing the diameter of the inner conductors, the flux linked by the turns of the toroidal geometry decreases, thus decreasing the inductance. To reclaim inductance, the number of turns in the inductor must be increased. By increasing the diameter of the inner turns, the number of turns, and the thickness of the conductor, $L / R$ ratios in the area of interest are attainable. It can also be seen that the parameters which increase the $L / R$ ratio also act to increase the mass of the inductor.

Iterations with an inductor design code were performed to identify the target values for inductance and resistance. The code uses Ampere's Law to calculate the magnetic energy stored in the volume of the inductor. This magnetic energy is equated to the inductive energy to solve for the inductance. The code uses a one-dimensional (1-D) diffusion model to calculate the losses associated with circulating currents formed during the transient charging of the inductor. Next, an equivalent ac resistance is calculated to account for transport and circulating current losses. These values are used in a very detailed system simulation to verify the performance of the proposed system. Basically, the inductor design code and the detailed simulation are used in an iterative fashion to optimize inductor geometry and the staged discharge timing of the system.

The proposed system resulting from this design methodology is shown in block diagram form in the lower half of figure 1. The design objective of increasing the transfer efficiency from HPG to inductor has been achieved. Transfer efficiency from the inductor to the railgun is enhanced by the greater inductance of the highefficiency inductors compared with the Balcones inductors. The switching losses are proportional to the inductance into which the current is being commutated, divided by the inductance of the storage inductor. The inductance of the commutation path is equivalent for both systems, but because the high-efficiency inductors have more inductance, switching losses are reduced. Also, the efficiency of the launcher in the RARDE program is simulated at a projectile velocity of $3,500 \mathrm{~m} / \mathrm{s}$, whereas the demonstrated Balcones system was operating just below $2,000 \mathrm{~m} / \mathrm{s}$. The dynamic impedance of the railgun is proportional to the product of the inductance gradient and the velocity. As the velocity of the launcher increases, the impedance associated with the electromechanical conversion dominates the circuit losses and proportionately more power goes into accelerating the projectile than into supplying system losses. Efficiency of the system increases with the projectile velocity.

In summary, detailed simulations that accurately predict the response of the Balcones power supply system for the 9-MJ SSG were used to simulate the performance of the RARDE program design. The resulting design includes four Balcones class HPGs operating at 6,850 rpm ( $92 \%$ of design speed) charging four energy storage inductors at $65 \%$ efficiency. The inductive stores are 
commutated via explosive opening switches into the rail launcher in a staged manner. The current pulse from the inductors accelerates a $2-\mathrm{kg}$ projectile to $3,500 \mathrm{~m} / \mathrm{s}(12 \mathrm{MJ}$ of kinetic energy) for an overall system efficiency of $23.5 \%$. This analysis has been presented as one example of the increased system efficiency possible with the new inductor configuration charged with a low impedance dc source.

\section{Inductor Specification}

A general specification for the high-efficiency inductors is given in figure 2 and table 1 . It can be seen from the description in table 1 that higher $L / R$ ratio (i.e., greater transfer efficiency) necessarily requires greater mass. This is an acceptable trade-off for a laboratorybased system. The cross section of the inductor is shown in figures 3 and 4 . The rounded end turns (fig. 3) greatly reduce the mechanical stress on the inductor. Construction of the inductor in octagonal sections makes shipping and handling easier and provides access for inspection and replacement of the turn-to-turn insulation. In table 2 , it can be seen that the operating current density and the current per input terminal is designed conservatively, compared with the demonstrated rating of the GEDI inductors. The fact that a higher inductor time constant, $L / R$, produces enhanced transfer efficiency is the result of simple circuit analysis.
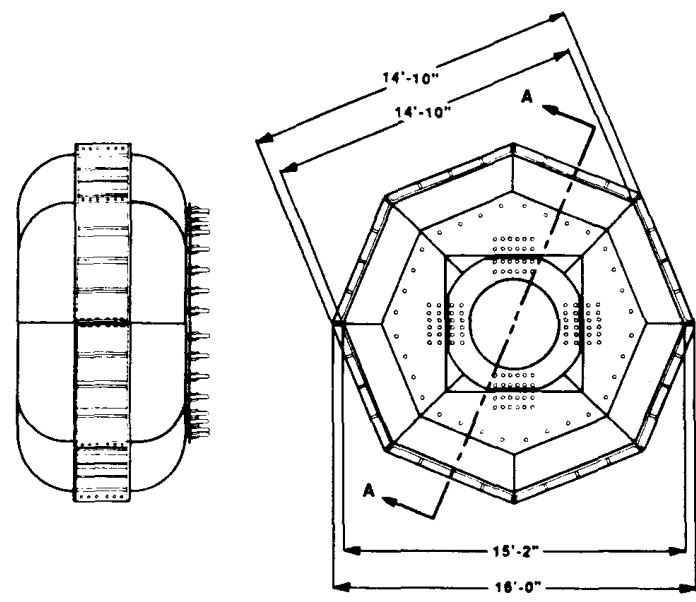

3701.0142

Figure 2. Inductor configuration

\section{Ideal Switching Efficiency in a Staged Inductive System [3]}

Staging inductive stores is an efficient method of maintaining a high average-to-peak acceleration ratio in a railgun discharge. In order to size staged inductive stores, the relationships for the ideal switching efficiency in the staged system must be known. The energy considerations for switching one inductive store into a railgun were presented in an earlier paper.[4] The parameters for a staged inductive circuit are shown in figure 5 . The analysis of this circuit begins at $t=t_{i}$, the initiation of switching. The initial conditions are

$$
\mathrm{I}_{\mathrm{s}}=\mathrm{I}_{\mathrm{si}}=\mathrm{I}_{\mathrm{xi}}
$$

Table 1. Energy storage inductors general specifications

5 Turn Toroidal Design

Room Temperature Copper

Removable Sections

Low Impedance

$\mathrm{L}=8.69 \mu \mathrm{H}$

$R=6.17 \mu \Omega$

No External Magnetic Fields

Replaceable Insulation System

Physical Parameters

Width $=4.62 \mathrm{~m}$

Height $=4.62 \mathrm{~m}$

Length $=2.13 \mathrm{~m}$

Weight $=28,200 \mathrm{~kg}$

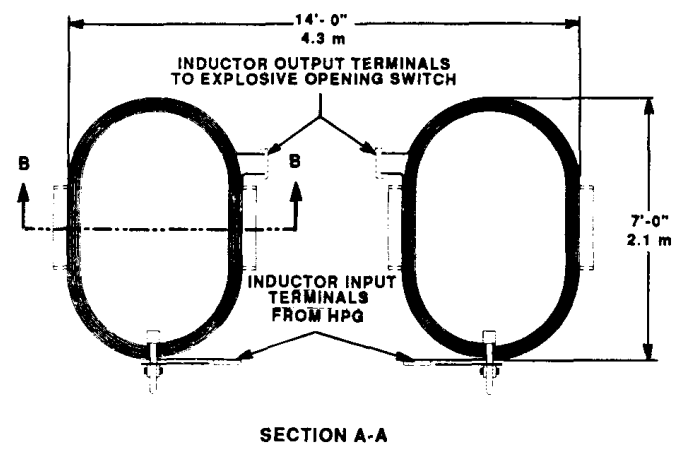

Figure 3. Inductor cross section \#2

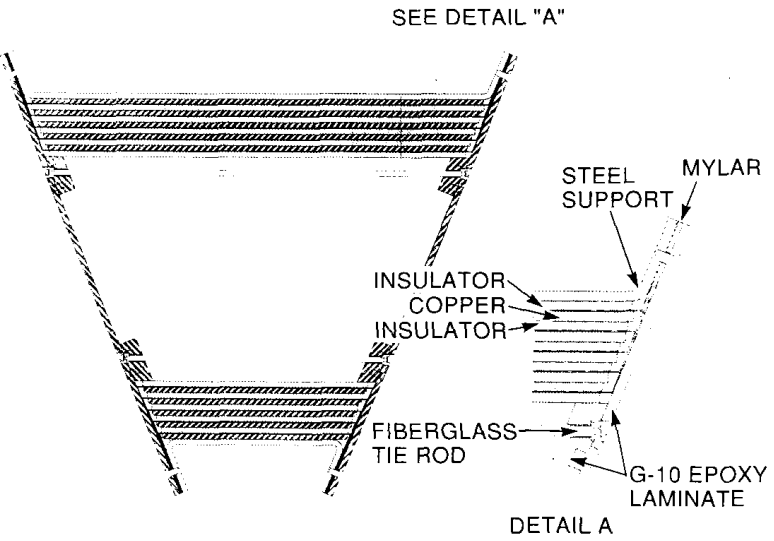

SECTION B-B

Figure 4. Octant cross section 
Table 2. Inductor characteristics

\begin{tabular}{|c|c|c|}
\hline & GEDI & $\begin{array}{c}\text { HIGH- } \\
\text { EFFICIENCY } \\
\text { INDUCTOR }\end{array}$ \\
\hline $\begin{array}{l}\text { Maximum Conductor } \\
\text { Current Density }\end{array}$ & $5,480{\mathrm{~A} / \mathrm{cm}^{2}}^{2}$ & $2,700 \mathrm{~A} / \mathrm{cm}^{2}$ \\
\hline \multirow{3}{*}{$\begin{array}{l}\text { High Charging Efficiency } \\
\text { L/R } \\
\text { HPG/IND Efficiency }\end{array}$} & & \\
\hline & 0.6 & 1.41 \\
\hline & $46 \%$ & $66 \%$ \\
\hline Trapped Flux & $11.8 \%$ & $6.4 \%$ \\
\hline \\
\hline Number & 16 & 32 \\
\hline t/Terminal & $78,125 \mathrm{~A}$ & $46,875 \mathrm{~A}$ \\
\hline
\end{tabular}

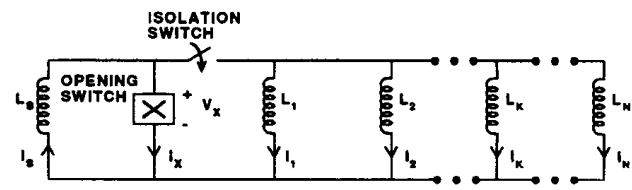

\section{$X=$ OPENING SWITCH
$S=$ STAGED INDUCTOR, ANY OF 1 THAU N}

$N=$ INDUCTIVE LOAD

3701.0145

Figure 5. Staged inductor circuit

The isolation switch is closed as the opening switch begins to open and Kirchoff's voltage law requires

$$
V_{x}=-\frac{d}{d t}\left(L_{s} I_{s}\right)=\frac{d}{d t}\left(L_{1} I_{1}\right)=\ldots=\frac{d}{d t}\left(L_{N} I_{N}\right)
$$

For $\mathrm{L}_{\mathbf{k}}$ constant or exhibiting very small change over the switching interval, then

$$
\frac{\mathrm{dI}_{\mathrm{s}}}{\mathrm{dt}}=-\frac{\mathrm{V}_{\mathrm{x}}}{\mathrm{L}_{\mathrm{s}}}, \quad \frac{\mathrm{dI}_{\mathrm{k}}}{\mathrm{dt}}=\frac{\mathrm{V}_{\mathrm{x}}}{\mathrm{L}_{\mathrm{k}}}
$$

Summing the currents at the common node gives

$$
I_{x}=I_{s}-\sum_{k=1 \neq 8}^{N} I_{k}
$$

The derivative of this expression is

$$
\frac{\mathrm{dI}_{\mathrm{x}}}{\mathrm{dt}}=\frac{\mathrm{dIs}}{\mathrm{dt}}-\sum_{\mathrm{k}=1 \neq \mathrm{s}}^{\mathrm{N}} \frac{\mathrm{dI}_{\mathrm{k}}}{\mathrm{dt}}=-\mathrm{V}_{\mathrm{x}}\left(\frac{1}{\mathrm{~L}_{\mathrm{s}}}+\sum_{\mathrm{k}=1 \neq \mathrm{s}}^{\mathrm{N}} \frac{1}{\mathrm{~L}_{\mathrm{k}}}\right)=-\mathrm{V}_{\mathrm{x}} \sum_{\mathrm{k}=1}^{\mathrm{N}} \frac{1}{\mathrm{~L}_{\mathrm{k}}}
$$

Solving for the switch voltage yields

$$
\mathrm{V}_{\mathrm{x}}=-\left(\frac{\mathrm{dI} \mathrm{I}_{\mathrm{x}}}{\mathrm{dt}}\right) \frac{1}{\sum_{\mathrm{k}=1}^{\mathrm{N}} \frac{1}{\mathrm{~L}_{\mathrm{k}}}}
$$

The currents after switching are then found by integrating the current derivatives over the switching interval $t_{i}$ to $t_{f}$.

$$
\int_{t_{i}}^{t_{f}} \frac{d I_{x}}{d t} d t=I_{x f}-I_{x i}=0-I_{s i}=-I_{s i}
$$

and

$$
\begin{aligned}
I_{s f} & =I_{s i}-\int_{t_{i}}^{t_{f}}\left(\frac{V_{x}}{L_{s}}\right) d t=I_{s i}-\int_{t_{i}}^{t_{f}} \frac{1}{L_{s}}\left(-\frac{d I_{x}}{d t}\right)\left(\frac{1}{\sum_{k=1}^{N} \frac{1}{L_{k}}}\right) d t \\
& =I_{s i}+\frac{1}{L_{s}\left(\sum_{k=1}^{N} \frac{1}{L_{k}}\right) t_{i}} \frac{d I_{x}}{d t} d t \\
& =I_{s i}\left(1-\frac{t_{f}}{L_{s}\left(\sum_{k=1}^{N} \frac{1}{L_{k}}\right)}\right.
\end{aligned}
$$

and

$$
I_{k f}=I_{k i}+\int_{t_{i}}^{t_{f}} \frac{V_{x}}{L_{k}} d t=I_{k j}+\frac{I_{s i}}{L_{k}\left(\sum_{k=1}^{N} \frac{1}{L_{k}}\right)}
$$

The general expression for the energy stored in the multiple inductor system is

$$
\mathrm{W}=\frac{1}{2} \mathrm{LI}_{\mathrm{s}}^{2}+\frac{1}{2} \mathrm{~L}_{1} \mathrm{I}_{1}^{2}+\ldots+\frac{1}{2} \mathrm{~L}_{\mathrm{N}} \mathrm{I}_{\mathrm{N}}^{2}
$$

The energy dissipated in the switching interval is defined as

$$
W_{i}-W_{f}
$$

These expressions can be applied to data from a staged railgun test to check their accuracy. Table 3 gives the experimental configuration for the Balcones system for test \#9 of the 9-MJ SSG. In this test, four inductive stores were discharged into the railgun via explosive opening switches at time zero and the fifth store was staged into the railgun at approximately $1.8 \mathrm{~ms}$ when the projectile was $1.5 \mathrm{~m}$ down the gun. Figures 6 and 7 give the staged inductor currents and the railgun current respectively. From these plots, the following data may be read. Before switching, the first four inductor currents are

$$
I_{2 i}=I_{3 i}=I_{5 i}=I_{6 i}=-640 \mathrm{kA}
$$

The staged inductor current before switching is

$$
I_{4 i}=I_{s i}=970 \mathrm{kA}
$$

and the railgun current after commutation is

$$
\mathrm{I}_{\mathrm{N}}=2,600 \mathrm{kA}
$$


Table 3. Circuit parameters for single-shot test \#9

\begin{tabular}{|ll|}
\hline \hline $\mathrm{L}_{1}$ & not used \\
$\mathrm{L}_{2}$ & $6.5 \mu \mathrm{H}$ discharged at time 0 \\
$\mathrm{~L}_{3}$ & $6.5 \mu \mathrm{H}$ discharged at time 0 \\
$\mathrm{~L}_{4}$ & $6.5 \mu \mathrm{H}$ staged at approximately $1.8 \mathrm{~ms}$ \\
$\mathrm{~L}_{5}$ & $6.5 \mu \mathrm{H}$ discharged at time 0 \\
$\mathrm{~L}_{6}$ & $6.5 \mu \mathrm{H}$ discharged at time 0 \\
$\mathrm{LN}_{\mathrm{N}}$ & railgun load, 200 $\mathrm{nH}($ bus inductance $)+$ \\
& $0.36 \mu \mathrm{H} / \mathrm{m} \times 1.5 \mathrm{~m}=0.74 \mu \mathrm{H}$ \\
\hline
\end{tabular}

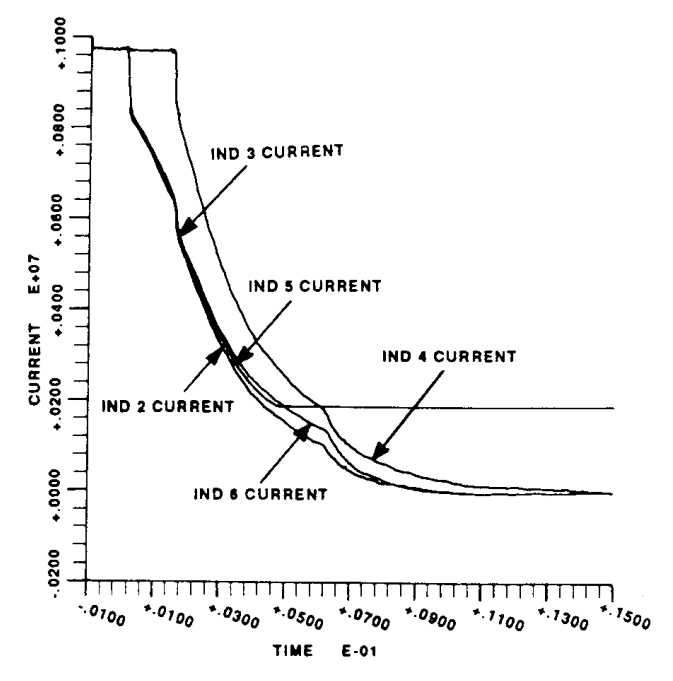

3701.0146

Figure 6. Staged inductor experimental current

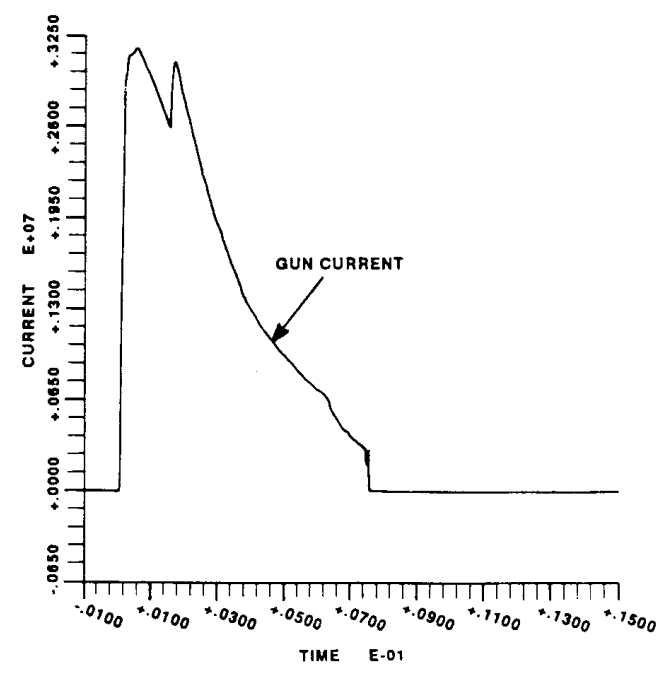

3701.0147

Figure 7. Railgun current from staged inductive discharge
Applying the formula for $\mathrm{I}_{\mathbf{k f}}$ yields

$$
\mathrm{I}_{2 \mathrm{f}}=\mathrm{I}_{3 \mathrm{f}}=\mathrm{I}_{5 \mathrm{f}}=\mathrm{I}_{6 \mathrm{f}}=-569 \mathrm{kA}
$$

which is in very good agreement with the experimental data. The calculated value for $I_{s f}$ is

$$
\mathrm{I}_{\mathrm{sf}}=899 \mathrm{kA}
$$

This value is overpredicting the experimental data by approximately $7 \%$. While the calculated value for the final railgun current, $\mathrm{I}_{\mathrm{Nf}}$, is

$$
\mathrm{I}_{\mathrm{Nf}}=3,215 \mathrm{kA}
$$

which overpredicts the experimental current by $6 \%$. The theoretical energy absorbed by the staged switch is calculated to be

$$
\mathrm{W}_{\mathrm{i}}-\mathrm{W}_{\mathrm{f}}=210 \mathrm{~kJ}
$$

The energy actually absorbed in the experiment which is calculated by multiplying the voltage across the staged opening switch by the current, through the switch and integrating over switching interval was found to be

$$
\mathrm{W}_{\exp }=315 \mathrm{~kJ}
$$

The theoretical value underpredicts the experimental switch loss by $23 \%$.

\section{Conclusions}

The design of the energy storage inductors for the RARDE pulse power supply is an iteration based on experience gained in the development and construction of the six inductor Balcones GEDI system and the compact cryogenic aluminum, five-turn coaxial inductors [5] designed by CEM-UT, built by PKD for CEM-UT and General Dynamics (GD). The GEDI industors are room temperature copper, two-turn coaxial inductors. The high-efficiency inductor is a room temperature, five-turn, all copper toroidal design with eight separate, removable sections for ease of maintenance and handling. Its toroidal design is similar to the five-turn compact inductors, though larger in size and with the addition of rounded end plates. The rounded end plates reduce the stress concentration found at the inside corners of the coaxial design, permitting the use of thinner material.

The proposed toroidal inductors have not been constructed. They are, however, designs based on proven analysis and construction techniques demonstrated in the manufacture of both the compact inductors for CEM-UT and GD and in the GEDI inductors for CEM-UT. In both of these previously manufactured inductor designs, the electrical parameters of the finished product exactly matched the code-predicted values; therefore, a high degree of confidence in the design and analysis process used in developing the torroidal inductor is warranted. In all cases, the new inductors are designed to produce lower conductor current densities and lower conductor stresses and stress concentration factors than those that occur in the proven GEDI inductors. These considerations, along with the use of the proposed robust replaceable insulation system for the torroidal inductors clearly indicates that the inductor will be highly reliable and easily maintainable. 
The expressions for the ideal switching efficiency for staged inductors have been derived and representative values calculated and compared to experimental results. The ideal switching analysis is adequate for the rough sizing of systems, but a full simulation is required to accurately predict losses.

\section{Ackmowledoments}

This research was supported by Brown and Root Vickers, Ltd. (BRV), Advanced Technology Design, Ltd. (ATD), and PKD under contract no. K21/21300.

\section{References}

1. W.L. Noble, J.M. Weldon, and J.H. Gully, "Final Manufacture and Assembly of a Modular 60 Megajoule Pulsed Homopolar Power Supply," IEEE Transactions on Magnetics, vol Mag-22, no. 6, November 1986, pp 1623-1627.

2. R.L. Laughlin, J.H. Gully, K.E. Nalty, and R.C. Zowarka, Jr., "System Design of the Ultrahigh Velocity GEDI Experiment," IEEE Transactions on Magnetics. vol Mag-22, no. 6, November 1986, pp 1578-1583.

3. J.P. Kajs, "Staged Inductor Ideal Efficiency Analysis," CEM-UT Internal Technical Note, TN-50, February 1990.

4. H.H. Woodson and W.F. Weldon, "Energy Considerations in Switching Current From an Inductive Store into a Railgun," 4th IEEE Pulsed Power Conference, Albuquerque, NM, 1983, pp 22-25.

5. M.L. Spann, S.B. Pratap, J.H. Gully, W.F. Weldon, and H.H. Woodson, "Fabrication of a Compact Storage Inductor for Railguns," IEEE Transactions on Magnetics, vol Mag-20, no. 2, March 1984, pp 215-218. 